\title{
What Attracts Men Who Batter to Their Partners? An Exploratory Study
}

Journal of Interpersonal Violence 26(I4) 2747-2763

(C) The Author(s) 2011

Reprints and permission: http://www. sagepub.com/journalsPermissions.nav

DOI: 10.1 I 77/0886260510390943 http://jiv.sagepub.com

\section{Daniel G. Saunders, PhD, MSSW', Jennifer F. Kurko, MSW, LCSW', Kirsten Barlow, MSW', and Colleen E. Crane, MSW'}

\begin{abstract}
Men who batter, because of particular personality traits and sense of entitlement, may select partners whom they perceive will be dependent on them, meet their emotional needs, or be "objects" of physical attractiveness. During treatment intake, 18I offenders responded to the question, "What attracted you to her (your partner)?" We explored whether men who mentioned their own needs or her physical traits would engage in more frequent and severe violence and would have specific forms of personality disorder dimensions or personality traits. Six categories of attraction, including "her physical traits" and "his needs," were derived from the men's responses. The results showed that men who focused on their partners' physical attractiveness were more likely to be violent after treatment. Men who cited their own needs for their attraction had higher scores on borderline personality, alcohol abuse, and psychotic thinking and lower scores on compulsive-conforming.
\end{abstract}

\section{Keywords}

batterers, domestic violence, violent offenders,

\footnotetext{
'School of Social Work, University of Michigan, Ann Arbor, MI

${ }^{2}$ College of Literature, Science and the Arts, University of Michigan, Ann Arbor, MI
}

\section{Corresponding Author:}

Daniel G. Saunders, School of Social Work, University of Michigan, 1080 South University, Ann Arbor, MI 48I09

Email: saunddan@umich.edu 
Research has not addressed the possibility that men who batter their intimate partners choose certain types of partners or that their reasons for partner selection are related to abuse or risk factors for abuse. One sign that men who batter seek physically vulnerable partners is that their partners tend to be below average in height and weight, whereas the men themselves are usually at the norm (Pagelow, 1981; Walker, 1984). That they try to create emotional vulnerability and dependency once in a relationship is demonstrated by frequent attempts to isolate their partners by disrupting support networks and interfering with job and school activities (Lloyd \& Taluc, 1999; Tjaden \& Thoennes, 2000; Tolman \& Rosen, 2001). Most research on the general process of mate selection finds that it is based on a similarity of traits, values, and interests; however, partner selection by men who batter is likely to be influenced by personality needs arising from their varied personality disorders and styles (Saunders, 2008).

Much extant research focuses on the reasons that women stay in abusive relationships (e.g., Barnett, Miller-Perrin, \& Perrin, 2004; Walker, Logan, Jordan, \& Campbell, 2004); however, studies have not addressed the reasons offenders are attracted to and remain with their partners. Although some research explores victim selection in cases of rape and child molestation, or focuses on why child abuse survivors might be vulnerable to being chosen by men who batter, no studies could be found that directly asked men who batter why they were attracted to their partners.

\section{Mate Selection Theories}

Contrary to the assumption that "opposites attract," more support is found for the theory that people choose partners who have similar attitudes, values, and attributes (e.g., Botwin, Buss, \& Shackelford, 1997; Buss \& Barnes, 1986; Byrne \& Nelson, 1965; Eckland, 1980). Consistent with this theory, people tend to marry someone who lives or works nearby or one with whom they have frequent contact (e.g., Bornstein, 1989). Attraction at first is usually based on similarity of backgrounds and later is based more on value similarity and compatible needs (Kerckhoff \& Davis, 1962). Social exchange theory and its variant, equity theory (Rhoades, Stanley, \& Markman, 2006), have been applied to understanding initial encounters. They illustrate how mutually rewarding exchanges lead to greater relationship investment and ultimately to a communal relationship (Huston \& Burgess, 1979). An important ingredient in mate selection may be the way in which one's partner reinforces one's sense of identity (McCall \& Simmons, 1966). (For reviews of these and other theories, see Caughlin \& Huston, 2010; Sassler, 2010.) 
Gender differences in mate selection have been studied from the perspectives of evolutionary psychology (e.g., Buunk, Dijkstra, Fetchenhauer, \& Kenrick, 2002) and social structure, among others (Howard, Blumstein, \& Schwartz, 1987), although the premises of evolutionary psychology have been challenged (e.g., Eastwick \& Finkel, 2008). According to evolutionary psychology, women prefer men who are intelligent, financially secure, and have high social status because these resources are needed for survival of their children. Men, however, are predicted to focus less on the social status of a potential partner and more on appearance, choosing someone who is relatively young and seems in the best health for bearing children. Men's preference for young, attractive women finds support in a national survey (Sprecher, Sullivan, Hatfield, 1994). Social structural theory interprets these results differently, asserting that women try to increase their own status by aligning with highstatus men, and men choose young women to assure greater dominance. Gender socialization theory posits that preferences will be based on stereotypic gender role expectations: Physical attractiveness and nurturance are associated with women and financial security and assertiveness with men (Doosje, Rojahn, \& Fischer, 1999).

\section{Victim Selection by Rapists and Sex Offenders}

Studies of rapists and sex offenders give some clues about victim selection by men who are violent. Stevens (1994) found that $66 \%$ of the rapists interviewed chose victims who "could not or would not" resist a sexual assault. Kirkendall (1980) found similar results for the rapists he studied. A number of studies show that when sex offenders are asked what they look for in a potential victim, many say they look for children and adolescents who have low self-esteem and appear to be lonely and emotionally needy (Budin \& Johnson, 1989; Conte, Wolf, \& Smith, 1989; Singer, Hussey, \& Strom, 1992).

\section{Child Sexual Abuse Survivors and Violent Relationships}

Several studies of battered women indicate that they are more likely to have suffered child sexual or physical abuse than women who are not battered (e.g., Astin, Lawrence, \& Foy, 1993; Coolidge \& Anderson, 2002; DiLillo, Giuffre, Tremblay, \& Peterson, 2001; Gelles, 1974; Walker, 1984). Similarly, child sexual abuse survivors have an increased vulnerability to physical and sexual assault as an adult (Wind \& Silvern, 1992). Childhood abuse could 
make women more vulnerable to selection by abusers because child abuse survivors are likely to have high rates of depression, anxiety, and posttraumatic stress disorder (Briere \& Runtz, 1987; Browne \& Finkelhor, 1986; Bryer, Nelson, Miller, \& Krol, 1987; Kendall-Tackett, Williams, \& Finkelhor, 1993; Polusny \& Follette, 1995).

\section{Partner Selection and Men Who Batter}

Typologies of men who batter may be useful in understanding their partner selection. The typology with the most empirical support includes three types: antisocial, borderline/dysphoric, and overly inhibited (Holtzworth-Munroe \& Meehan, 2004; Holtzworth-Munroe, Meehan, Herron, Rehman, \& Stuart, 2000). The antisocial type has a long history of violent behavior inside and outside the family and a long history of substance abuse. He uses intimidation to maintain dominance and tends to have a dismissive attachment style. He uses violence instrumentally and tends to justify it. He suffered the most severe physical abuse in childhood. The borderline/dysphoric type fears abandonment, shows extreme jealousy and impulsivity, and may become suicidal. His anxious attachment style most likely developed from losses, rejections, and humiliations in childhood. The overly inhibited type tries to suppress his emotions, is violent only at home, and exhibits less severe and less frequent violence than other types. He has the least hostility toward women. Antisocial offenders tend to be the most hostile and domineering toward women (Holtzworth-Munroe et al., 2000) and are likely to objectify them. In contrast, borderline/dysphoric offenders tend to be the most emotionally needy and, with strong fears of abandonment, tend to be extremely possessive (Dutton \& Golant, 1995; Dutton \& Haring, 1999). These types and their attachment styles are consistent with findings of other researchers. Jacobson \& Gottman (1998), for example, describe an antisocial abuser as "adept at finding women who are vulnerable to their macabre charisma, women whose lives are guided by a particular kind of dream, women who are down on their luck ... " (p. 92). They describe a borderline/dependent type of abuser as viewing himself as a victim and as psychologically needy: "The women they chose tended to have similar histories and the women felt as though it was their responsibility to help the man change." Severe forms of psychopathology and personality disorders may be related directly to recidivism after treatment, although such a relationship has not been consistently found (Gondolf \& White, 2001).

The present study explored reasons given by men who batter for their attraction to their partners. It also examined whether particular types of 
attraction could be predictably linked with particular personality disorders. Finally, we explored the relationship among reasons for attraction, violence history, and recidivism. We expected that abusive men with narcissistic or borderline personalities might be attracted to their mates based on the woman's ability to fulfill their emotional needs and that men with antisocial personalities would be attracted to their mates' physical features. We further expected that men who expressed positive, rather than superficial, reasons for choosing their mates (commonalties, positive personality traits) would engage in fewer acts of violence.

\section{Method}

\section{Participants}

Data for this study were collected from male offenders during the intake process at a community-based domestic violence program from male offenders $(n=181)$ and from a subsample of their partners before $(n=77)$ and after treatment $(n=107)$ (For more information on the treatment program see Saunders, 1996). The men had been referred primarily by a deferred prosecution program (17\%) or probation department following prosecution $(59 \%)$, with others referred by social service agencies, attorneys, friends, family members, or themselves. The average age of the men was $32.4(S D=8.3)$. Of the sample, 14\% were African American, 3\% were non-White Hispanic, 4\% were Native American, $1 \%$ Asian, with the remainder White/EuroAmerican (78\%). Their average income was US\$13,435 per year $(S D=$ US\$10,162). Eighteen percent had not completed high school, $23 \%$ had attended some college, $11 \%$ had earned college degrees, and $2 \%$ had attended some graduate school. Their average years of education were 12.6 $(S D=1.9)$. A seven-page, semistructured assessment interview, conducted by an intake worker, was administered to each participant. The 181 men who responded to the question "What attracted you to her (to your mate)?" were included in the analysis, with 136 of the 181 in the analysis of posttreatment measures.

\section{Procedure}

Although most were referred by the criminal justice system, all the men were required to call the program for an appointment. They normally attended four to six individual intake sessions. In addition to obtaining a comprehensive 
history of past help-seeking, substance abuse, suicide potential, childhood violence, relationship violence, and other areas, these sessions included attempts to increase the man's motivation for change, decrease his minimizing about abusive behavior, and develop a control plan. The men completed a series of self-administered measures of personality, attitudes, behavior, and affect.

\section{Measures}

Millon Clinical Multiaxial Inventory (MCMI). The MCMI was used to assess the personality traits and disorders of the men (Millon, 1983). It contains 175 items that measure eight personality and character disorders (Axis II), three chronic and dysfunctional personality disorders (Axis II), and nine circumscribed or transient clinical syndromes. The MCMI shows good internalstructural validation and external validity with many other measures. It contains corrections for psychological defensiveness, self-deprecation, and denial tendencies. For some analyses, factor scores from five factors were used: (a) dependent/somataform; (b) drug abuse/alcohol abuse/narcissistic/ hypomanic/antisocial; (c) avoidant/borderline/anxious/depressed; (d) paranoid; and (e) compulsive/passive-aggressive.

Attraction to partner. A question during the intake process asked about the current relationship of the participant: "What attracted you to her?" Responses to the question were divided into six initial categories by three of the authors. Next, three research assistants assigned each response to one of the six categories. The 181 men produced a total of 423 responses for an average of 2.3 responses per person. Up to four responses were coded for each respondent: $25 \%$ had one response coded; $39 \%$ had two; $25 \%$ had three; and $10 \%$ had four. The rate of agreement between two of the raters was $87 \%$. The third rater's scores were used to resolve any disagreements there might have been between the first two raters. There was a $93 \%$ agreement rate between all three raters after the disagreements between scores had been resolved. The remaining unresolved ratings were discussed among the raters until an agreement was reached.

The six categories are described in the appendix. One category was labeled His Needs. Responses in this category dealt with characteristics that would fulfill his needs. Responses such as "she was easy to talk to" and "I wanted companionship" were included in this category. The second category was titled Her Needs. This category classified the batterers' responses in relation to the partner's needs and possible needs the batterer thought he could fulfill. Examples of responses placed in this category were "I thought I could help her" or "I felt sorry for her." The third category was labeled Nonphysical Characteristics. This category included responses dealing with the partner's 
personality, behavioral, and emotional characteristics. Some examples from this category were "she's fun to be with" and "she is intelligent." The fourth category was titled Physical Characteristics. Any responses indicating a physical attraction, such as "her looks" or "her smile" were placed in Category 4. Category 5 was named Commonalties. This category included responses that indicated similarities between the two as the source of attraction. Responses in this category included "similar interests," "similar beliefs," and "similar goals."

The category titled Nonphysical Traits was divided into four subcategories. The first subcategory was labeled Behavior. It included responses that dealt with the partner's behaviors, mannerisms, or actions - for example "sense of humor," "her style," and "risk taking." The next subcategory was labeled Specific Personality Traits. It included specific descriptors such as "outgoing," "shy," and "caring." Certain personality traits were taken from this last category and used to create a separate category, Independent, Strong, Tough and Stable. The final category, Miscellaneous, contained responses that did not fit into other categories. "Independent, Strong, Tough and Stable" had only seven responses and was collapsed into "Specific Personality Traits."

Violence. Violence recidivism information was available for program completers and was measured primarily with reports from the men's partners ( $n=107$ of 136 cases) an average of 22 months after a 20 session treatment program. Any form of physical abuse was included, either from an expanded version of the Conflict Tactics Scales (Straus \& Gelles, 1990) or a three-item version that condensed these scales. (The shortened version was used in follow-up stages to increase the response rate.) In addition, state arrest records were searched for domestic violence arrests. In one case, the follow-up report from an abuser was used to supplement the victim report and arrest records. Interviews with victims were conducted primarily by telephone. A total of $79 \%$ of victims were contacted and cooperated with the interviews.

Violence before treatment was measured with an expanded version of the Physical Aggression Scale of the Conflict Tactics Scales (Straus \& Gelles, 1990). Additional items included driving recklessly to frighten her, burn her, and two items on sexual abuse. The response format ranged from none to more than three times a week, with 10 increments. Information was obtained from all abusers and 77 of their partners. The partners' reports were used when available.

\section{Results}

The men's reasons for being attracted to their partners were distributed as follows: "Her Nonphysical Characteristics" (70\%); "Her Physical Characteristics" (66\%); "His Needs" (20\%); "Their Commonalities" (12\%); and "Her 
Table I. Percentage of Reasons for Attraction in Total and Overlap Among the Responses

\begin{tabular}{lcccccc}
\hline & $\begin{array}{c}\text { Total } \\
\text { percentage } \\
\text { of } \\
\text { responses }\end{array}$ & $\begin{array}{c}\text { Her } \\
\text { nonphysical } \\
\text { traits (\%) }\end{array}$ & $\begin{array}{c}\text { Her } \\
\text { physical } \\
\text { traits } \\
(\%)\end{array}$ & $\begin{array}{c}\text { His } \\
\text { needs } \\
(\%)\end{array}$ & $\begin{array}{c}\text { Commonalities } \\
(\%)\end{array}$ & $\begin{array}{c}\text { Her } \\
\text { needs } \\
(\%)\end{array}$ \\
\hline $\begin{array}{l}\text { Her nonphysical } \\
\text { traits }\end{array}$ & 70 & - & 48.2 & 14.0 & 5.7 & 2.3 \\
$\begin{array}{l}\text { Her physical } \\
\text { traits }\end{array}$ & 66 & & - & 9.9 & 11.0 & 4.1 \\
$\begin{array}{l}\text { His needs } \\
\begin{array}{l}\text { Commonalities } \\
\text { Her needs }\end{array}\end{array}$ & 20 & & & - & 3.6 & 0.0 \\
\hline
\end{tabular}

Needs" (4\%). The percentages total more than $100 \%$ because more than one reason could be coded per respondent. Table 1 shows these percentages as well as the percentage of overlap among the response categories. Analysis indicated significant associations among several categories: His Needs and Her Physical Traits $\left(\chi^{2}=14.4 ; p<.001\right)$; His Needs and Her Nonphysical Traits $\left(\chi^{2}=4.6 ; p<.05\right)$; Commonalities and Her Nonphysical Traits $\left(\chi^{2}=13.7\right.$; $p<.001)$; and Her Nonphysical Traits and Her Needs $\left(\chi^{2}=4.2 ; p=.05\right)$.

The MCMI subscale scores were not related to the category "Her Physical Characteristics," whether using independent $t$ tests for any mention of this as a reason versus no mention of this as a reason (see Table 2) or using ANOVA comparing no mention of the characteristic, mention of one characteristic, or mention of two characteristics in this category. However, given the considerable overlap among responses, a more "pure" form of the measure was used that removed the overlap with other categories. The resulting composite measure correlated positively with the Histrionic $(r=.17, p<.05)$, Somatoform $(r=.17, p<.05)$, and Drug Abuse Subscales $(r=.14 ; p=.06)$ and correlated negatively with the Schizotypal $(r=-.16, p<.05)$ and Psychotic Thinking Subscales $(r=.13, p=.07)$.

The MCMI subscale scores shown in Table 2 compare those who cited "His Needs" as a reason for attraction versus those who did not. The average borderline personality score was significantly higher among those stating "His Needs." Narcissistic subscale scores did not differ between the two groups. Scores for alcohol abuse and psychotic thinking were significantly 
Table 2. Comparisons Between Those Who Did and Did Not Report Attraction for "His Needs" and "Her Physical Traits" on the MCMI Personality and Personality Disorders Scales

\begin{tabular}{|c|c|c|c|c|c|c|c|c|}
\hline & \multicolumn{4}{|c|}{ "His Needs" } & \multicolumn{4}{|c|}{ “Her Physical Traits” } \\
\hline & & $M$ & $S D$ & $t$ & & $M$ & $S D$ & $t$ \\
\hline \multirow[t]{2}{*}{ Schizoid-asocial } & Yes & 40.0 & 24.4 & & Yes & 40.9 & 26.8 & \\
\hline & No & 39.3 & 26.4 & -0.12 & No & 38.8 & 25.4 & 0.61 \\
\hline \multirow[t]{2}{*}{ Avoidant } & Yes & 44.8 & 29.7 & & Yes & 42.5 & 30.9 & \\
\hline & No & 40.1 & 29.2 & -0.69 & No & 41.6 & 28.2 & 0.84 \\
\hline \multirow[t]{2}{*}{ Dependent } & Yes & 55.8 & 30.1 & & Yes & 57.8 & 27.0 & \\
\hline & No & 58.4 & 26.2 & $0.4 I$ & No & 58.4 & 25.7 & 0.89 \\
\hline \multirow[t]{2}{*}{ Histrionic } & Yes & 65.6 & 17.4 & & Yes & 66.6 & 17.7 & \\
\hline & No & 66.5 & 18.7 & 0.23 & No & 66.7 & 17.9 & 0.96 \\
\hline \multirow[t]{2}{*}{ Narcissistic } & Yes & 70.0 & 17.7 & & Yes & 72.2 & 23.2 & \\
\hline & No & 71.3 & 20.2 & 0.27 & No & 71.7 & 18.0 & 0.88 \\
\hline \multirow[t]{2}{*}{ Antisocial-aggressive } & Yes & 66.8 & 25.1 & & Yes & 68.9 & 21.1 & \\
\hline & No & 66.1 & 20.1 & -0.14 & No & 65.9 & 21.0 & 0.36 \\
\hline \multirow[t]{2}{*}{ Compulsive-conforming } & Yes & 50.1 & 23.2 & & Yes & 58.0 & 19.5 & \\
\hline & No & 58.5 & 19.9 & $1.69 * *$ & No & 60.4 & 50.4 & 0.70 \\
\hline \multirow[t]{2}{*}{ Passive-aggressive } & Yes & 56.4 & 33.1 & & Yes & 51.5 & 28.0 & \\
\hline & No & 50.5 & 30.1 & -0.82 & No & 60.4 & 83.3 & 0.36 \\
\hline \multirow[t]{2}{*}{ Schizotypal } & Yes & 45.4 & 14.8 & & Yes & 55.6 & 21.1 & \\
\hline & No & 43.6 & 19.7 & -0.41 & No & 59.3 & 17.5 & 0.51 \\
\hline \multirow[t]{2}{*}{ Borderline } & Yes & 56.0 & 21.2 & & Yes & 48.9 & 21.6 & \\
\hline & No & 50.0 & 15.3 & $-1.19 *$ & No & 52.4 & 18.3 & 0.26 \\
\hline \multirow[t]{2}{*}{ Paranoid } & Yes & 63.5 & 13.0 & & Yes & 65.5 & 16.8 & \\
\hline & No & 64.0 & 17.0 & 0.12 & No & 63.5 & 15.8 & 0.43 \\
\hline \multirow[t]{2}{*}{ Anxiety } & Yes & 57.6 & 28.0 & & Yes & 55.6 & 31.2 & \\
\hline & No & 58.6 & 28.5 & 0.15 & No & 59.3 & 25.6 & 0.41 \\
\hline \multirow[t]{2}{*}{ Somatoform } & Yes & 55.1 & 15.8 & & Yes & 54.1 & 18.0 & \\
\hline & No & 56.4 & 17.9 & 0.31 & No & 56.7 & 16.4 & 0.33 \\
\hline \multirow[t]{2}{*}{ Hypomania } & Yes & 53.3 & 25.1 & & Yes & 49.2 & 27.1 & \\
\hline & No & 50.2 & 26.6 & -0.52 & No & 52.4 & 25.9 & 0.44 \\
\hline \multirow[t]{2}{*}{ Dysthymia } & Yes & 56.7 & 25.0 & & Yes & 51.8 & 30.8 & \\
\hline & No & 55.0 & 30.9 & -0.26 & No & 56.3 & 29.3 & 0.33 \\
\hline \multirow[t]{2}{*}{ Alcohol abuse } & Yes & 60.5 & 18.9 & & Yes & 53.1 & 19.5 & \\
\hline & No & 50.5 & 20.6 & $-2.14 * *$ & No & 53.4 & 19.9 & 0.94 \\
\hline
\end{tabular}


Table 2. (continued)

\begin{tabular}{|c|c|c|c|c|c|c|c|c|}
\hline & \multicolumn{4}{|c|}{ "His Needs" } & \multicolumn{4}{|c|}{ "Her Physical Traits" } \\
\hline & & M & $S D$ & $t$ & & M & $S D$ & $t$ \\
\hline \multirow[t]{2}{*}{ Drug abuse } & Yes & 67.4 & 18.8 & & Yes & 67.7 & 19.4 & \\
\hline & No & 66.4 & 18.2 & -0.24 & No & 67.7 & 17.6 & 0.97 \\
\hline \multirow[t]{2}{*}{ Psychotic thinking } & Yes & 55.0 & 16.0 & & Yes & 51.5 & 17.5 & \\
\hline & No & 49.0 & 16.4 & $-1.51 *$ & No & 50.3 & 16.2 & 0.65 \\
\hline \multirow[t]{2}{*}{ Psychotic delusion } & Yes & 47.8 & 15.7 & & Yes & 62.2 & 33.3 & \\
\hline & No & 43.9 & 19.9 & -0.96 & No & 57.0 & 17.9 & 0.20 \\
\hline \multirow[t]{2}{*}{ Psychotic depression } & Yes & 58.1 & 22.1 & & Yes & 44.0 & 20.9 & \\
\hline & No & 57.8 & 17.8 & -0.08 & No & 45.0 & 17.8 & 0.75 \\
\hline
\end{tabular}

Note: $\mathrm{MCMI}=$ Millon Clinical Multiaxial Inventory

$* p<.10 .{ }^{*} p<.05$.

Table 3. Relationship Between Attraction for Physical Reasons and Recidivism After Treatment

\begin{tabular}{lccc}
\hline Recidivism & No reason $(n=47)$ & One reason $(n=79)$ & Two reasons $(n=10)$ \\
\hline Yes & $36 \%$ & $47 \%$ & $70 \%$ \\
No & $64 \%$ & $53 \%$ & $30 \%$
\end{tabular}

Kendall's Tau-B $=1.89 *$

$* p<.05$

higher for those reporting "His Needs" and compulsive-conforming scores were significantly lower for this group.

Only one MCMI subscale score was related to the category "Her Nonphysical Traits": If no trait was mentioned, the Antisocial-Aggressive subscale mean was 70.7 ; if one trait was mentioned, it was 64.6; if two traits were mentioned, it was 66.7 ; and if three traits were mentioned, it was 55.4 $(F=1.88 ; p=.04)$.

The categories "Their Commonalities" and "Her Needs" had too few participants for analysis.

Being attracted to partners because of their physical traits was significantly related to recidivism (see Table 3 ). Seventy percent of those giving two physical traits as reasons for attraction and $47 \%$ giving one reason were violent after treatment, compared with only $36 \%$ who did not give this reason (Kendall's Tau-B $=1.89 ; p=.05$ ). When the variables were dichotomized 
and the overlap with other responses was removed, $59 \%$ of those who gave at least one physical trait as a reason for attraction were violent after treatment, compared with $39 \%$ who did not give this reason $\left(\chi^{2}=1.9 ; p=.08\right)$.

Two categories of partner selection were also related to violence in the year before treatment. Those who responded with "His Needs" reported that they more frequently "pushed, carried, restrained, grabbed, or shoved" in the year before treatment $(t=-2.12 ; p=.03)$. Choosing a partner for "Her Physical Traits" was related to "hit or tried to hit with something" $(t=-1.69$; $p=.04)$ and "threw her bodily" $(t=-1.75 ; p=.04)$. The category of selection called "Nonphysical Characteristics" was generally related to less violence before treatment and reached significance for one item: Those in this group reported lower frequency for "pushed, carried, restrained, grabbed, or shoved" in the year before treatment $(t=1.65 ; p=.05)$.

MCMI scores were not related to recidivism after treatment. However, scores on the borderline scale were related to the frequency of screaming $(r=.27$; $p=.003)$, smashing objects $(r=.29 ; p=.002)$, and driving recklessly to frighten the partner $(r=.22 ; p=.03)$ in the year prior to treatment.

In a multivariate analysis, the combination of reasons for selecting a partner accounted for $4.6 \%$ of variance in explaining recidivism $(F=1.14, n s)$. The combination of MCMI scores accounted for $21 \%$ of variance in recidi$\operatorname{vism}(F=1.27, n s)$, and reasons for attraction added about $7 \%$ more in a hierarchical analysis $(F$ of change $=1.75 ; n s)$. Path analysis was not conducted because the specific personality variables were not significantly related to outcome variables.

\section{Discussion}

Approximately, two thirds of abusers cited physical and/or nonphysical traits of their partners as the reasons they were attracted to them. Approximately, $20 \%$ cited their own needs and a small percentage cited her needs or what the couple had in common. The finding on physical traits is consistent with views of abusers as possessive in the sense that they could regard an attractive partner as a "prize possession." The results run counter to findings in the general population - that having characteristics in common is a major source of attraction-but fits with findings on men's general propensity to value physical attractiveness. A significant relationship was found between citing one's own needs as the reason for attraction and attraction due to both her physical and nonphysical traits. By contrast, those who cited her nonphysical traits were more likely to say that her needs and what the couple had in common were the sources of attraction. 
As expected, borderline personality was related to the partner selection category called "His Needs." The alcohol abuse and psychotic thinking subscales were also higher for those reporting "His Needs." These personality traits also suggest emotional neediness that could lead to the selection of a partner in an attempt to fulfill such needs. "Psychotic Thinking" on the MCMI is related to thought patterns in some alcoholics as opposed to the thought patterns of schizophrenics (Millon, 1997).

Attraction to her "Nonphysical Traits" was related to lower scores on the Anti-Social-Aggressive subscale. The type of personality disorder was not related to recidivism. However, borderline tendencies were related to higher frequencies of forms of violence prior to treatment that would be expected to be signs of borderline disorder: screaming, smashing objects, and driving recklessly to frighten.

Attraction to physical traits was related to recidivism after treatment and frequency of some forms of violence before treatment. This finding suggests that more superficial reasons for attraction involve objectification of the partner and thus an increased likelihood of eventual abuse. Patterns of attraction and violent behavior noted above can be interpreted within findings from previous research on types of men who batter (Holtzworth-Munroe et al., 2000). In particular, differences between borderline-dysphoric batterers, characterized by fears of abandonment and emotional volatility, have been contrasted with generalized aggressors who have antisocial traits. Emotional neediness and forms of violence of the borderline type in this study are consistent with previous typology research.

These findings need to be considered within the context of their limitations. First, reports of attraction by men who batter could have been affected by social desirability response bias. Second, sample sizes for some categories of partner selection were relatively small and could have led to an underestimation of significant effects. Third, the measure of attraction was based on a single question, with its reliability and validity evidence being given in this study for the first time. More extensive measures of attractiveness would be ideal, including more extensive qualitative measures as well as some standardized instruments that are available (e.g., Shoshtrom \& Knapp, 1977).

Despite these limitations, this study adds to our knowledge of the constellation of abuser traits. Asking about initial attractions may be a less threatening way for men to reveal their characteristics. To the extent that partner selection by abusers is tied to their traits and behavior, it shifts the focus from asking "Why did she seek out a violent partner?" and "Why does she stay with him?" to asking "What is he looking for in a partner?" In particular, "Rather 
than an equal partner, is he seeking someone who is vulnerable and will quickly become dependent or someone he considers an attractive object?"

\section{Appendix}

\section{Categories of Attraction to One's Partner}

Category I: His Needs. Responses in this category reflect the partner's ability to fulfill a need in the abuser. These needs are mainly emotional, in particular the ability to give and receive love. The spouse's characteristics made the abuser feel more comfortable with himself and life in general. For example, "she was easy to talk to" or "I wanted companionship" were classified as "his needs."

Category 2: Her Needs. Responses in this category indicate the abuser's source of attraction was one of consideration for his partner's unmet emotional needs. Responses such as "I thought I could help her" or "I felt sorry for her" are included in this category.

Category 3: Nonphysical Characteristics. Responses in this category included a variety of behaviors and personality traits. Behaviors included "sense of style," "communication style," or "the way she handles herself." Specific personality descriptors, such as "outgoing," "shy," or "caring" were also included in this category, as well as neutral or general personality descriptors such as having a "nice" personality.

Category 4: Physical Characteristics. Responses in this category reflected bodily attributes of the women the abuser found attractive. These tended to be superficial characteristics. Responses such as "her looks" or "her smile" were included.

Category 5: Commonalties. This category included responses that indicate the attraction was due to similarities between the two. For instance, responses such as "similar interests," "similar beliefs," or "similar goals" were included. Category 6: Miscellaneous. All responses that did not fit into the above categories were placed into this category.

\section{Declaration of Conflicting Interests}

The authors declared no potential conflicts of interest with respect to the authorship and/or publication of this article.

\section{Funding}

The authors received no financial support for the research and/or authorship of this article. 


\section{References}

Astin, M. C., Lawrence, K. J., \& Foy, D. W. (1993). Posttraumatic stress disorder among battered women: Risk and resiliency factors. Violence and Victims, 8(1), $17-28$.

Barnett, O. W., Miller-Perrin, C. L., \& Perrin, R. D. (2004). Family violence across the lifespan: An introduction (2nd ed.). Thousand Oaks, CA: SAGE.

Bornstein, R. F. (1989). Exposure and affect: Overview and meta-analysis of research, 1968-1987. Psychological Bulletin, 106, 265-289.

Botwin, M. D., Buss, D. M., \& Shackelford, T. K. (1997). Personality and mate preferences: Five factors in mate selection and marital satisfaction. Journal of Personality, 65(1), 107-136.

Briere, J., \& Runtz, M. (1987). Post sexual abuse trauma: Data and implications for clinical practice. Journal of Interpersonal Violence, 2, 367-379.

Browne, A., \& Finkelhor, D. (1986). The impact of child sexual abuse: A review of the research. Psychological Bulletin, 99(1), 66-77.

Bryer, J. B., Nelson, B. A., Miller, J. B., \& Krol, P. A. (1987). Childhood sexual and physical abuse as factors in adult psychiatric illness. American Journal of Psychiatry, 144, 1426-1430.

Budin, L. E., \& Johnson, C. F. (1989). Sex abuse prevention programs: Offenders' attitudes about their efficacy. Child Abuse \& Neglect, 13, 77-87.

Buss, D. M., \& Barnes, M. (1986). Preferences in human mate selection. Journal of Personality \& Social Psychology, 50, 559-570.

Buunk, B. P., Dijkstra, P., Fetchenhauer, D., \& Kenrick, D. T. (2002). Age and gender differences in mate selection criteria for various involvement levels. Personal Relationships, 9, 271-278.

Byrne, D., \& Nelson, D. (1965). Attraction as a linear function of proportion of positive reinforcements. Journal of Personality and Social Psychology, 1, 659-663.

Caughlin, J. P., \& Huston, T. L. (2010). The flourishing literature on flourishing relationships. Journal of Family Theory \& Review, 2, 25-35.

Conte, J. R., Wolf, S., \& Smith, T. (1989). What sexual offenders tell us about prevention strategies. Child Abuse \& Neglect, 13, 293-301.

Coolidge, F. L., \& Anderson, L. W. (2002). Personality profiles of women in multiple abusive relationships. Journal of Family Violence, 17(2), 117-131.

DiLillo, D., Giuffre, D., Tremblay, G. C., \& Peterson, L. (2001). A closer look at the nature of intimate partner violence reported by women with a history of child sexual abuse. Journal of Interpersonal Violence, 16(2), 116-132.

Doosje, B., Rojahn, K., \& Fischer, A. (1999). Partner preferences as a function of gender, age, political orientation and level of education. Sex Roles: A Journal of Research, 40, 45-60. 
Dutton, D. G., \& Golant, S. K. (1995). The batterer: A psychological profile. New York, NY: Basic Books.

Dutton, D. G., \& Haring, M. (1999). Perpetrator personality effects on post-separation victim reactions in abusive relationships. Journal of Family Violence, 14, 193-204.

Eastwick, P. W., \& Finkel, E. J. (2008). Sex differences in mate preferences revisited: Do people know what they initially desire in a romantic partner? Journal of Personality and Social Psychology, 94, 245-264.

Eckland, B. K. (1980). Theories of mate selection. In J. M. Henslin (Ed.), Marriage and family in a changing society (pp. 132-140). New York, NY: Free Press.

Gelles, R. J (1974). The Violent Home: AStudy of Physical Aggression Between Husbands and Wives. Beverly Hills, CA: SAGE.

Gondolf, E. W., \& White, R. J. (2001). Batterer program participants who repeatedly reassault: Psychopathic tendencies and other disorders. Journal of Interpersonal Violence, 16, 361-380.

Holtzworth-Munroe, A., \& Meehan, J. C. (2004). Typologies of men who are maritally violent: Scientific and clinical implications. Journal of Interpersonal Violence, 19, 1369-1389.

Holtzworth-Munroe, A., Meehan, J. C., Herron, K., Rehman, U., \& Stuart, G. L. (2000). Testing the Holtzworth-Munroe and Stuart (1994) batterer typology. Journal of Consulting and Clinical Psychology, 68, 1000-1019.

Howard, J. A., Blumstein, P., \& Schwartz, P. (1987). Social or evolutionary theories: Some observations on preferences in human mate selection. Journal of Personality and Social Psychology, 53, 194-200.

Huston, T. L., \& Burgess, R. L. (1979). Social exchange in developing relationships: An overview. In R. L. Burgess \& T. L. Huston (Eds.), Social exchange in developing relationships (pp. 3-28). New York, NY: Academic Press.

Jacobson, N. S., \& Gottman, J. M. (1998). When men batter women: New insights into ending abusive relationships. New York, NY: Simon \& Schuster.

Kendall-Tackett, K. A., Williams, L. M., \& Finkelhor, D. (1993). The impact of sexual abuse on children: A review and synthesis of recent empirical studies. Psychological Bulletin, 113, 164-180.

Kerckhoff, A. C., \& Davis, K. (1962). Value consensus and need complementarity in mate selection. American Sociological Review, 27, 295-303.

Kirkendall, A. R. (1980, October). Victim selection processes involved in rape. Dissertation Abstracts International, 41(4-B), 1567.

Lloyd, S., \& Taluc, N. (1999). The effects of male violence on female employment. Violence Against Women, 5, 370-392.

McCall, G. J., \& Simmons, J. L. (1966). Identities and interactions. New York, NY: Free Press. 
Millon, T. (1983). Millon Clinical Multiaxial Inventory. Minneapolis, MN: National Computer Systems.

Millon, T. (1997). The Millon Inventories: Clinical and personality assessment. New York, NY: Guilford.

Pagelow, M. D. (1981). Woman-battering: Victims and their experiences. Beverly Hills, CA: SAGE.

Polusny, M. A., \& Follette, V. M. (1995). Long-term correlates of child sexual abuse: Theory and review of the empirical literature. Applied and Preventive Psychology, $4,143-166$.

Rhoades, G. K., Stanley, S. M., \& Markman, H. J. (2006). Pre-engagement cohabitation and gender asymmetry in marital commitment. Journal of Family Psychology, 20, 553-560.

Sassler, S. (2010). Partnering across the life course: Sex, relationships, and mate selection. Journal of Marriage and Family, 72, 557-575.

Saunders, D. G. (1996). Feminist cognitive behavioral and process psychodynamic treatments for men who batter: Interactions of abuser traits and treatment models. Violence and Victims, 11, 393-414.

Saunders, D. G. (2008). Personality characteristics of batterers. In C. Renzetti \& J. Edleson (Eds.), Encyclopedia of interpersonal violence (pp. 68-69). Thousand Oaks, CA: SAGE.

Shoshtrom, F. L., \& Knapp, R. R. (1977). Relationship between clinical ratings and inventory measures of intrapersonal styles: Validity of the Pair Attraction Inventory. Educational and Psychological Measurement, 37, 541-543.

Singer, M. I., Hussey, D., \& Strom, K. J. (1992). Grooming the victim: An analysis of a perpetrator's seduction letter. Child Abuse \& Neglect, 16, 877-886.

Sprecher, S., Sullivan, Q., \& Hatfield, E. (1994). Mate selection preferences: Gender differences examined in a national sample. Journal of Personality and Social Psychology, 66, 1074-1080.

Stevens, D. J. (1994). Predatory rapists and victim selection techniques. Social Science Journal, 31, 421-433.

Straus, M. A., \& Gelles, R. J. (1990). Physical violence in American families: Risk factors and adaptations to violence in 8,145 families. New Brunswick, NJ: Transaction Publishing.

Tjaden, P., \& Thoennes, N. (2000). Prevalence and consequences of male-to-female and female-to-male intimate partner violence as measured by the National Violence Against Women Survey. Violence Against Women, 6, 142-161.

Tolman, R. M., \& Rosen, D. (2001). Domestic violence in the lives of women receiving welfare. Violence Against Women, 7, 141-158.

Walker, L. E. (1984). The battered woman syndrome. New York, NY: Springer. 
Walker, R., Logan, T. K., Jordan, C. E., \& Campbell, J. C. (2004). An integrative review of separation in the context of victimization: Consequences and implications for women. Trauma Violence Abuse, 5, 143-193.

Wind, T. W., \& Silvern, L. (1992). Type and extent of child abuse as predictors of adult functioning. Journal of Family Violence, 7, 261-281.

\section{Bio}

Daniel G. Saunders, $\mathrm{PhD}$, MSSW, is a professor at the University of Michigan School of Social Work, Ann Arbor. His research, teaching, and service focus on the problems of dating and domestic violence. He has published more than 70 articles and book chapters, primarily on offender program effectiveness, the traumatic effects of victimization, and the response of professionals to survivors of domestic violence.

Jennifer F. Kurko, is a licensed clinical social worker in Long Island, New York, specializing in early childhood interventions and work with home-bound students. She is a graduate of the master of social work program at the School of Social Work, University of Michigan.

Kirsten Barlow, is an Associate Director, Legislation and Public Policy, at the California Mental Health Directors Association. In this position, as well as in her prior work at the California Department of Mental Health and Los Angeles County Department of Mental Health, she is an advocate for resources that assist in the recovery of persons with serious mental illness and serious emotional disturbance. She has also worked for the California State Legislature as a committee consultant on human services programs. She earned her B.A. in psychology at the University of Michigan, and M.S.W. at the University of California at Berkeley.

Colleen E. Crane, is a social worker in Bozeman, Montana. Her clinical interests include work with maltreated and pregnant adolescents and domestic violence survivors. Her research interests focus on domestic violence and child abuse and neglect. 